This item was submitted to Loughborough's Research Repository by the author.

Items in Figshare are protected by copyright, with all rights reserved, unless otherwise indicated.

\title{
Prediction of acoustic emissions of turbocharger bearings
}

PLEASE CITE THE PUBLISHED VERSION

https://saemobilus.sae.org/content/2020-01-1504

PUBLISHER

SAE

VERSION

AM (Accepted Manuscript)

PUBLISHER STATEMENT

This paper was accepted for publication in the journal SAE Technical Paper and the definitive published version is available at https://doi.org/10.4271/2020-01-1504

\section{LICENCE}

CC BY-NC-ND 4.0

\section{REPOSITORY RECORD}

Dolatabadi, Nader, Ramin Rahmani, and Homer Rahnejat. 2020. "Prediction of Acoustic Emissions of Turbocharger Bearings". Loughborough University. https://hdl.handle.net/2134/13242317.v1. 


\title{
Prediction of Acoustic Emissions of Turbocharger Bearings
}

\author{
N. Dolatabadi, R. Rahmani, H. Rahnejat \\ Wolfson School of Mechanical, Electrical and Manufacturing Engineering, Loughborough University, Leicestershire, UK
}

\begin{abstract}
Turbochargers are progressively used in modern automotive engines to enhance engine performance and reduce energy loss and adverse emissions. Use of turbochargers along with other modern technologies has enabled development of significantly downsized internal combustion engines. However, turbochargers are major sources of acoustic emissions in modern automobiles. Their acoustics has a distinctive signature, originating from fluid-structure interactions. The bearing systems of turbochargers also constitute an important noise source. In this case, the acoustic emissions can mainly be attributed to hydrodynamic pressure fluctuations of the lubricant film. The developed analytical model determines the lubricant pressure distribution in the floating journal bearings used mainly in the modern turbocharges. This allows for an estimation of acoustic emissions. The use of such an analytical approach is computationally efficient when compared with full numerical analysis approaches, whilst also providing reliable predictions. The results from the developed analytical model are used to determine the power loss as well as sound pressure levels generated in the turbocharger bearings due to oil flow which can be correlated with the acoustic emissions of turbochargers.
\end{abstract}

Keywords: Rotordynamics; Turbocharger; Floating Ring Journal Bearings; Acoustic Emissions

\section{Introduction}

Downsizing internal combustion (IC) engines plays an important part in meeting the ever-stringent emission regulations. These engines invariably use turbochargers in order to increase their power-toweight ratio. However, use of turbochargers has resulted in new challenges in countering the resulting noise pollution from the vehicle powertrain system. Specific to the turbochargers is the experience of a continual whining noise within the passenger cabin. This noise is normally associated with self-excited lateral rotor vibrations termed as oil whirl. This phenomenon occurs due to the highly non-linear stiffness characteristics of the floating ring journal bearings (in particular the inner lubricant film) used in the modern turbochargers [1]. The rotor sub-synchronous instability is also of concern when oil whirl or whip is present even in turbochargers with a floating ring bearing design [2].

There have been a significant number of reported investigations of rotordynamics of floating ring turbochargers, for example [3-8]. Schweizer and Sievert [4] and San Andres et al [5] have investigated the non-linear dynamics of turbochargers, whilst Brouwer et al [6] measured journal whirl and friction characteristics of turbochargers

Page 1 of 7 with floating rings and ball bearings. They found that the motion of ball bearing turbocharger mainly included synchronous whirl, whereas that of a floating ring bearing is dominated by subsynchronous whirl for the entire range of operating speeds. In addition, the ball bearing turbochargers showed lower frictional losses. Smilik et al [7] found that bearing clearance can generate and determine the magnitude of sub-synchronous components of the rotor response. Koutsovasilis et al [8] developed a dynamic model for a turbocharger with a full floating ring bearing and quantified the associated sub-synchronous vibrations. They concluded that a considerable amount of system overall response is dependent on the design of outer clearances. They also noted the significance of bearing's outer width. Therefore, it seems that the acoustic emissions from the floating ring journal bearings used in the automotive turbochargers are mostly an unexplored area, warranting further investigations.

In the current study, an analytical quasi-static model for finite-width floating ring bearings based on "short" journal bearing assumption [9] is developed. The approach is similar to a method developed originally by Mokhtar [10] for the case of an infinite-width floating ring bearing based on a "long" journal bearing assumption. Then, the sound pressure levels are calculated based on the determined pressure fluctuations in the journal bearings, similar to the method reported by Rho and Kim [11]. Such method has already been used to evaluate the acoustic emissions from big end bearing used in IC engines operating with cylinder deactivation (CDA) technology [12].

\section{Methodology}

A floating ring journal bearing model is developed for the study of a turbocharger bearings. Figure 1 is a schematic representation of the studied turbocharger arrangement.

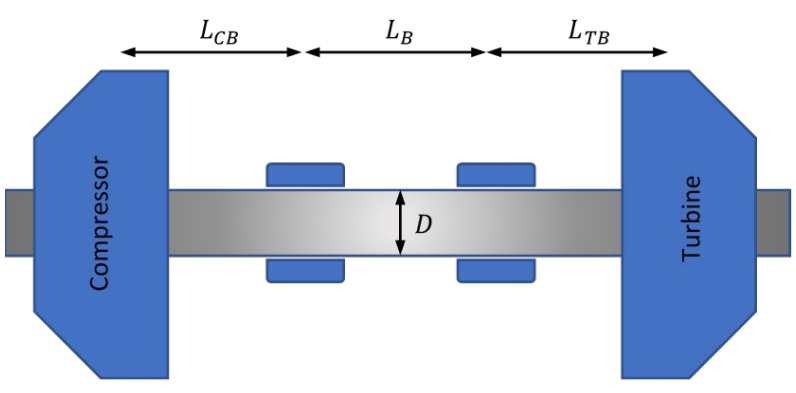

Fig. 1: Schematic of the studied turbocharger arrangement 


\section{Floating Ring Journal Bearing Model}

The shaft (journal) and the floating ring eccentricities are denoted by $e_{j r}$ and $e_{b r}$ respectively (Figure 2). The rotational speeds of shaft and floating ring are $N_{j}$ and $N_{r}$, respectively. Friction torques $M_{r, i}$ and $M_{r, o}$ are related to the lubricant viscous shear at the inner and the outer surfaces of the floating ring. Under quasi-static conditions, these generated torques equilibrate. Figure 2 shows the case where the two eccentricities are aligned. This condition might not hold under all operating conditions and the attitude angle $\phi$ might slightly differ for the shaft (journal) and the floating ring. The following simplifying assumptions are made:

- The bearing operates under hydrodynamic regime of lubrication

- The bearing is considered to have a short width

- Half-Sommerfeld boundary condition is assumed

- Quasi-static conditions are assumed with no inertial dynamics

In the case of the studied turbocharger, length (or lateral width) to diameter ratios; $L / D$ are approximately 0.58 and 0.63 for the inner and the outer floating ring interfaces. Therefore, short-width journal bearing theory is used. This assumption enables the use of a simple analytical solution for the study of hydrodynamic lubrication, based on Reynolds equation. The proposed analytical approach is deemed to be time efficient and relatively simple and accurate.

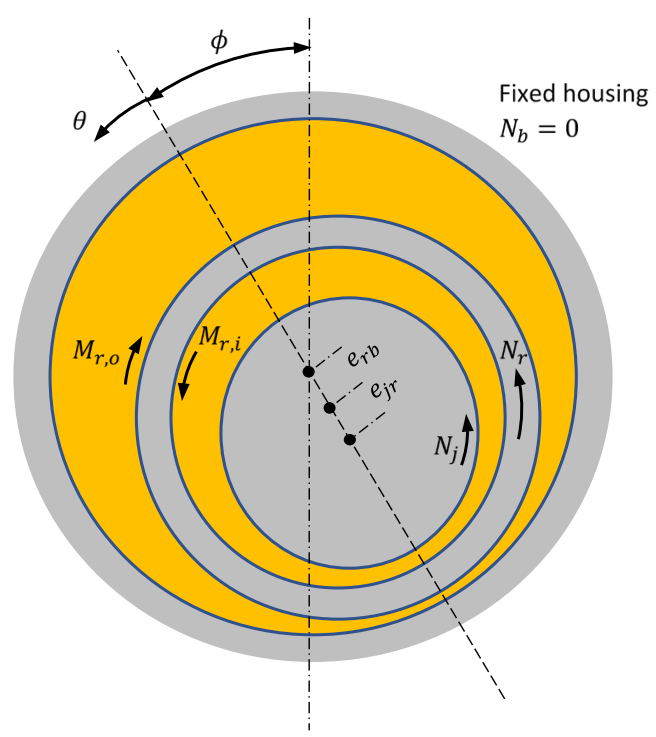

Fig. 2: Schematics of the floating ring journal bearing for the case of aligned attitude angles for rotor and the floating ring

Reynolds equation for short-width journal bearing approximation is [9]:

$\frac{\mathrm{d}}{\mathrm{d} z}\left(\frac{h^{3}}{\eta} \frac{\mathrm{d} p}{\mathrm{~d} z}\right)=12 U \frac{\mathrm{d} h}{\mathrm{~d} x}$

where, $p, \eta$ and $U$ are pressure, dynamic viscosity and entrainment velocity respectively. Coordinates $x$ and $z$ are the peripheral and lateral directions of the bearing. The dimensionless pressure distributions at the shaft-floating ring and floating ring-bearing conjunctions can be calculated by integration of Eq. (1), yielding:

$$
\begin{aligned}
& \bar{p}_{j r}(\bar{z})=3\left(1+\frac{\omega_{r}}{\omega_{j}}\right)\left(\frac{1}{4}-\bar{z}^{2}\right) \frac{\varepsilon \sin \theta}{(1+\varepsilon \cos \theta)^{3}}+\bar{p}_{j r, i} \\
& \bar{p}_{b r}(\bar{z})=3\left(\frac{1}{4}-\bar{z}^{2}\right) \frac{\varepsilon \sin \theta}{(1+\varepsilon \cos \theta)^{3}}+\bar{p}_{b r, i}
\end{aligned}
$$

The following relationships were used to yield non-dimensional representations:

$x=R \theta, h=C(1+\varepsilon \cos \theta), \varepsilon=\frac{e}{C}, p=\eta N\left(\frac{L}{C}\right)^{2} \bar{p}$

Subscripts $j r$ and $b r$ refer to the shaft (journal)-floating ring and floating ring-bearing housing conjunctions respectively. Gumbel (half-Sommerfeld) boundary condition is applied for the calculation of pressures and friction torques. The actual Sommerfeld number, $\Delta_{a}$, is evaluated at each conjunction as:

$\Delta_{j r, a}=\frac{W\left(\frac{c_{j r}}{L_{j r}}\right)^{2}}{L_{j r} R_{j r} \eta \omega_{j}}, \Delta_{b r, a}=\frac{W\left(\frac{c_{b r}}{L_{b r}}\right)^{2}}{L_{b r} R_{b r} \eta \omega_{r}}$

The predicted Sommerfeld numbers from analytical model, $\Delta_{p}$, varies with the eccentricity ratios $\varepsilon_{j r}$ and $\varepsilon_{b r}$ :

$\Delta_{j r, p}=\frac{\pi}{4} \frac{\varepsilon_{j r}^{2}}{\left(1-\varepsilon_{j r}^{2}\right)^{2}} \sqrt{\left(\frac{16}{\pi^{2}}-1\right) \varepsilon_{j r}^{2}+1}\left(1+\frac{\omega_{r}}{\omega_{j}}\right)$
$\Delta_{b r, p}=\frac{\pi}{4} \frac{\varepsilon_{b r}^{2}}{\left(1-\varepsilon_{b r}^{2}\right)^{2}} \sqrt{\left(\frac{16}{\pi^{2}}-1\right) \varepsilon_{b r}^{2}+1}$

Provided the predicted eccentricity ratios are correct, the corresponding Sommerfeld numbers in equations (4) and (5) should be identical. The quasi-static solution imposes quasi-static equilibrium between the two lubricant films, thus: $W=W_{j r}=W_{b r}$. Hence, a relationship between the rotational speeds of shaft (journal) and the floating ring can be established as:

$\frac{N_{j}}{N_{r}}=\frac{R_{b r} C_{j r}^{2} L_{b r}^{3}}{R_{j r} C_{b r}^{2} L_{j r}^{3}} \frac{\varepsilon_{b r}^{2}\left(1-\varepsilon_{j r}^{2}\right)^{2}}{\varepsilon_{j r}^{2}\left(1-\varepsilon_{b r}^{2}\right)^{2}} \frac{\sqrt{\left(\frac{16}{\pi^{2}}-1\right) \varepsilon_{b r}^{2}+1}}{\sqrt{\left(\frac{16}{\pi^{2}}-1\right) \varepsilon_{j r}^{2}+1}}-1$

Friction torques at the inner and the outer surfaces of the floating ring should remain at quasi-static equilibrium. Friction at these surfaces is mainly due to the Couette flow (viscous shear), because the pressure gradient is fairly negligible, based on the short journal bearing approximation. The viscous shear stress can be calculated at each conjunction as:

$\tau_{j r}=\frac{R\left(\omega_{j}-\omega_{r}\right) \eta}{h}, \tau_{b r}=\frac{R \omega_{r} \eta}{h}$

The dimensionless friction at each conjunction can be related to the eccentricity ratios $\varepsilon_{j r}$ and $\varepsilon_{b r}$, as:

$$
\begin{aligned}
\frac{F_{f, j r} C_{j r}}{\eta R_{j r}^{2} L_{j r} \omega_{j}} & =\frac{\pi}{\left(1-\varepsilon_{j r}^{2}\right)^{1 / 2}}\left(1-\frac{\omega_{r}}{\omega_{j}}\right) \\
\frac{F_{f, b r} C_{b r}}{\eta R_{b r}^{2} L_{b r} \omega_{r}} & =\frac{\pi}{\left(1-\varepsilon_{b r}^{2}\right)^{1 / 2}}
\end{aligned}
$$

Page 2 of 7

$10 / 19 / 2016$ 
Under quasit-static equilibrium, the friction torque equilibrium condition is satisfied if: $M_{r, i}=M_{r, o}$ :

$F_{f, b r} R_{b r}=F_{f, j r} R_{j r}$

This equation provides a second relationship between the rotational speeds of shaft and the floating ring using the eccentricity ratios $\varepsilon_{j r}$ and $\varepsilon_{b r}$ :

$\frac{N_{j}}{N_{r}}=\left(\frac{R_{b r}}{R_{j r}}\right)^{3}\left(\frac{L_{b r}}{L_{j r}}\right)\left(\frac{C_{j r}}{C_{b r}}\right)\left(\frac{\eta_{b r}}{\eta_{j r}}\right) \frac{\left(1-\varepsilon_{j r}^{2}\right)^{1 / 2}}{\left(1-\varepsilon_{b r}^{2}\right)^{\frac{1}{2}}}+1$

Thus, equations (6) and (10) should be solved simultaneously in order to satisfy the load balance and friction torque equilibrium conditions. There are three unknowns and two equations. Therefore, a simple iterative routine is adopted to determine the eccentricity ratios. Shaft speed, $N_{j}$, is known and the bearing physical parameters are listed in Table 1. The unbalanced load, $W$, and the actual Sommerfeld number for shaft $\left(\Delta_{j r, a}\right)$ can be calculated under quasistatic conditions. An initial guess value is assumed for the eccentricity ratio $\varepsilon_{j r}$. The eccentricity ratio $\varepsilon_{b r}$ is determined through the simultaneous solution of equations (6) and (10). These eccentricity ratios should satisfy the load and friction toque equilibria. Eccentricity ratios should also provide identical results for actual and predicted Sommerfeld numbers. Otherwise, the initial guessed eccentricity ratio $\varepsilon_{j r}$ is incorrect and should be iteratively modified in order to reduce the error between the actual and predicted Sommerfeld numbers $\left(\Delta_{j r, a}\right.$ and $\left.\Delta_{j r, p}\right)$. The eccentricity ratio at each iteration step is updated as:

$\varepsilon_{j r, n}=\varepsilon_{j r, o}+\chi\left(\frac{\Delta_{j r, a}-\Delta_{j r, p}}{\Delta_{j r, a}}\right)$

where, the constant $\chi$ is the relaxation factor, considered as 0.01 in the current study. The subscripts ' $n$ ' and ' $o$ ' refer to "new" and "old" predictions of the eccentricity ratio $\varepsilon_{j r}$ during the iterative procedure. The convergence criterion is set to $10^{-4}$.

Lubricant viscosity is known at certain reference temperatures. Vogel's empirical equation is utilised to predict the viscosity at the operating temperature [8]:

$\eta=7.5713 \times 10^{-5} \exp \left(\frac{1066.8814}{T-151.6230}\right)$

where, the temperature $T$ is in Kelvins.

\section{Oil Whirl Analysis}

In journal bearings, the shaft inertia induces whirling vibrations through the stiffness and damping of the lubricant film. Often, the frequency of whirling for a one-dimensional bearing model is obtained in terms of lubricant film stiffness only as:

$f=\frac{1}{2 \pi} \sqrt{\frac{k_{\text {oil }}}{m_{j}}}$

However, bearings undergo two-dimensional whirling vibrations in the presence of damping. Hence, a more comprehensive approach is essential to identify oil whirl and whip frequencies [12]. The dimensionless shaft speed $\Omega=\omega \sqrt{C / g}$ is used for this purpose,

Page 3 of 7 where $\omega, C$ and $g$ are shaft's angular speed in ( $\mathrm{rad} / \mathrm{s})$, bearing clearance and gravitational acceleration, respectively. This is the approach also used in [12], where a stability chart comprising many numerical solutions for journal bearing conditions is used to ascertain the stability of given operating conditions.

The attitude angles at each of the floating bearing conjunctions are given as:

$\phi_{j r}=\tan ^{-1}\left(\frac{\pi}{2} \frac{\sqrt{1-\varepsilon_{j r}^{2}}}{\varepsilon_{j r}}\right)$

$\phi_{b r}=\tan ^{-1}\left(\frac{\pi}{2} \frac{\sqrt{1-\varepsilon_{b r}^{2}}}{\varepsilon_{b r}}\right)$

The 'dynamic resilience' of the oil film is given as [13]:

$G=\frac{\varepsilon}{\Delta} \frac{\mathrm{d} \Delta}{\mathrm{d} \varepsilon}$

Subsequently, the whirl/whip frequency $\lambda$ can be estimated through the solution of the following characteristic equation [13]:

$\lambda^{4}+\frac{\lambda^{3}}{\Omega} \frac{4 \sin \phi}{\varepsilon}+\lambda^{2}\left[(G+1) \frac{\cos \phi}{\varepsilon}-\sin \phi \frac{\mathrm{d} \phi}{\mathrm{d} \varepsilon}+\frac{4}{\varepsilon^{2} \Omega^{2}}\right]-\frac{2 \lambda}{\Omega} \frac{\mathrm{d} \phi}{\mathrm{d} \varepsilon}+\frac{G}{\varepsilon^{2}}=0(16)$

The proposed methodology approximates the whirl frequency using simplified quasi-static analysis. The whirl frequency results would be more accurate if inertial dynamics of shaft and floating ring are also taken into account.

\section{Sound Pressure Level Model}

Oil pressure distributions for the steady state response of the bearing are utilised to predict the sound pressure level, based on the approach presented in $[11,12]$. The in-situ sound pressure levels are calculated using the deviation of maximum generated pressure from the average in each of the two conjunctions. The average pressure is determined as:

$p_{m}=\frac{1}{T_{c}} \int_{t}^{t+T_{c}} p \mathrm{~d} t$

Subsequently, sound pressure level is calculated in decibels as:

$S P L(d B)=20 \log \left(\frac{p_{\max }-p_{m}}{p_{\text {ref }}}\right)$

where, the reference pressure, $p_{\text {ref }}=20 \times 10^{-6} \mathrm{~Pa}$.

\section{Results and Discussion}

A turbocharger design was selected from a published research in open literature [8] in order to examine the performance of the proposed analytical model in this study. The physical properties of this turbocharger are presented in Table 1. The proposed analytical model in this paper differs from that in [8] from various aspects. For the simplicity of the analytical method, steps in the shaft design and the oil feed holes on the floating ring are neglected. In addition, Koutsovasilis [8] solves a 2D form of Reynolds equation 
numerically. Furthermore, shaft dynamics is neglected in the current study and quasi-static conditions are assumed. Hence, some degrees of discrepancy in the results would be expected from those presented in [8].

Table 1: Physical properties of a turbocharger [8]

\begin{tabular}{lll}
\hline Parameter & Value & Unit \\
\hline Total length of rotor assembly, $L_{t o t}$ & 100 & $\mathrm{~mm}$ \\
Reference length, $L=L_{C B}+L_{B}+L_{T B}$ & 65 & $\mathrm{~mm}$ \\
Total mass of the rotor assembly, $m_{t o t}$ & 70 & $\mathrm{~g}$ \\
Bearing ring inner diameter, $d_{r, i n}$ & 6 & $\mathrm{~mm}$ \\
Bearing ring outer diameter, $d_{r, o u t}$ & 9.5 & $\mathrm{~mm}$ \\
Bearing ring inner width, $L_{r, i n}$ & 3.5 & $\mathrm{~mm}$ \\
Bearing ring outer width, $L_{r, o u t}$ & 6 & $\mathrm{~mm}$ \\
Reference bearing shaft diameter, $d_{j}$ & 6 & $\mathrm{~mm}$ \\
Unbalance at compressor, $m_{u c}$ & $2 \times 0.03$ & $\mathrm{~g} . \mathrm{mm}$ \\
Unbalance at Turbine, $m_{u t}$ & $2 \times 0.03$ & $\mathrm{~g} . \mathrm{mm}$ \\
Dynamic oil viscosity $@ 20^{\circ} \mathrm{C}, \eta_{o}$ & 0.142 & $\mathrm{~Pa} . \mathrm{s}$ \\
Oil supply temperature, $T$ & 90 & ${ }^{\circ} \mathrm{C}$ \\
Rotor speed, $\Omega_{j}$ & $0-3 \times 10^{5}$ & $\mathrm{RPM}$ \\
Inner clearance, $C_{j r}$ & 21.07 & $\mu \mathrm{m}$ \\
Outer clearance, $C_{r b}$ & 69.86 & $\mu \mathrm{m}$ \\
\hline
\end{tabular}

Figure 3 shows that lubricant pressure is relatively higher at the journal-floating ring conjunction at the speed of 300,000 RPM. This is partially due to a smaller clearance in this conjunction in comparison with the floating ring-bearing contact, as well as a narrower contact width. Side leakage in narrow-width bearings imposes a pressure drop at the edges of the bearing as shown in Figure 3.
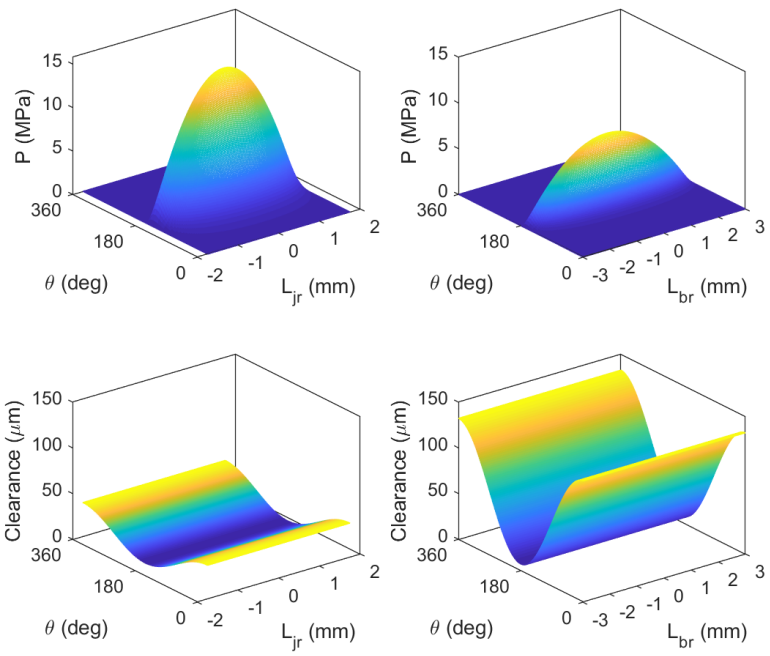

Fig. 3: Pressure distributions and clearance variations at shaftfloating ring conjunction (left) and at floating ring and bearing conjunction (right) at 300,000 RPM
Figure 4 shows the central pressure distribution and clearance variations along the periphery of the bearing at two different speeds. At the lower speed of $5000 \mathrm{RPM}$, contact pressure is rather insignificant due to the lower speed of lubricant entrainment into the contact as well as a smaller unbalanced load. The unbalance increases with rising shaft velocity, so do the generated pressures from a few $\mathrm{kPa}$ (Figure 4a) to approximately $16 \mathrm{MPa}$ at the speed of 300,000 RPM (Figure 4b).

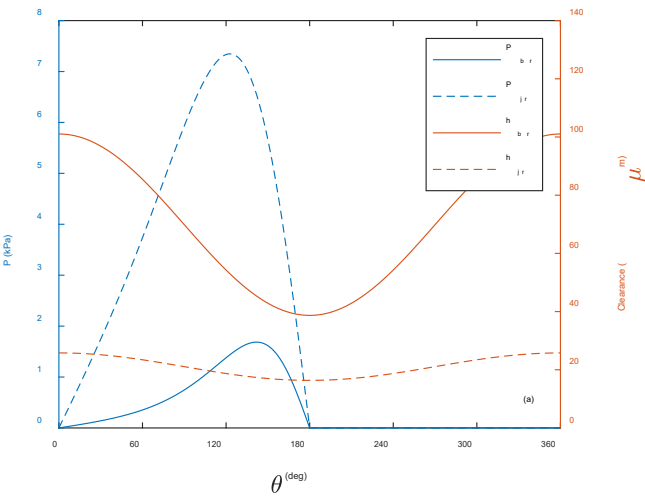

(a)

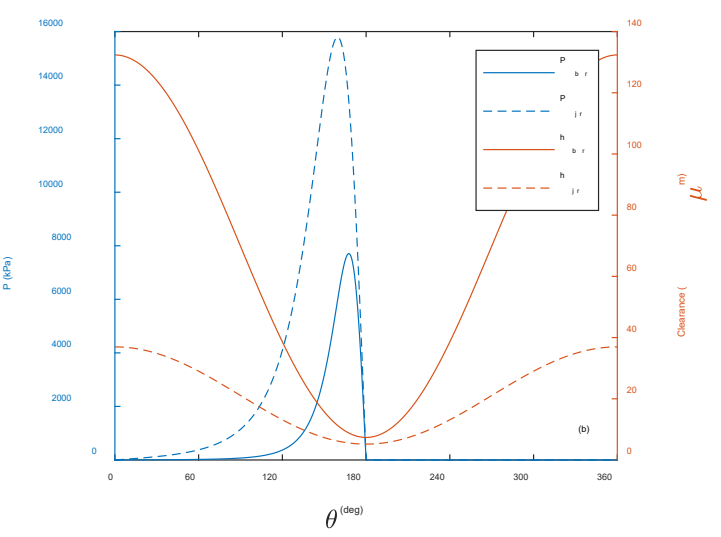

(b)

Fig. 4: Pressure distribution and clearance variation at the shaftfloating ring and floating ring-bearing conjunctions at (a) $5000 \mathrm{rpm}$ and (b) $300,000 \mathrm{rpm}$

In the hydrodynamic regime of lubrication, film thickness is expected to rise with increasing entrainment velocity. This is not the case for turbochargers due to an increase in the unbalanced load with shaft speed as is shown in Figure 5.

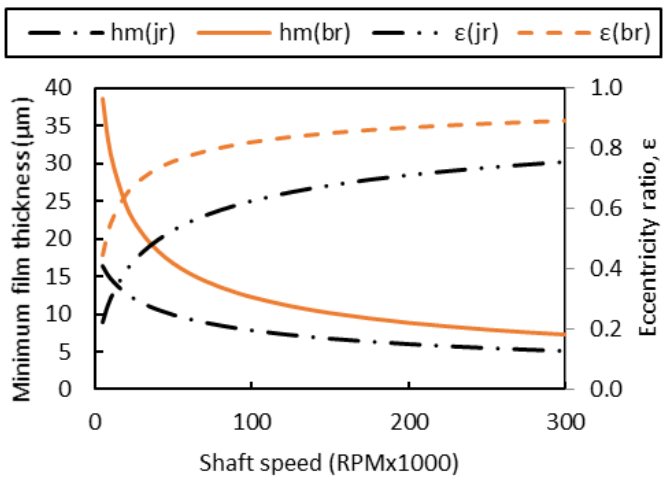

Fig. 5: Variations of minimum film thickness, $h_{m}$, and eccentricity ratios, $\varepsilon$, with shaft speed (unbalance load) at the shaft-floating ring and floating ring-bearing conjunctions

Page 4 of 7 
Figure 6 shows the corresponding attitude angles. These angles decrease for both shaft and floating ring with an increase in shaft speed, whilst the deviation between these angles also increases.

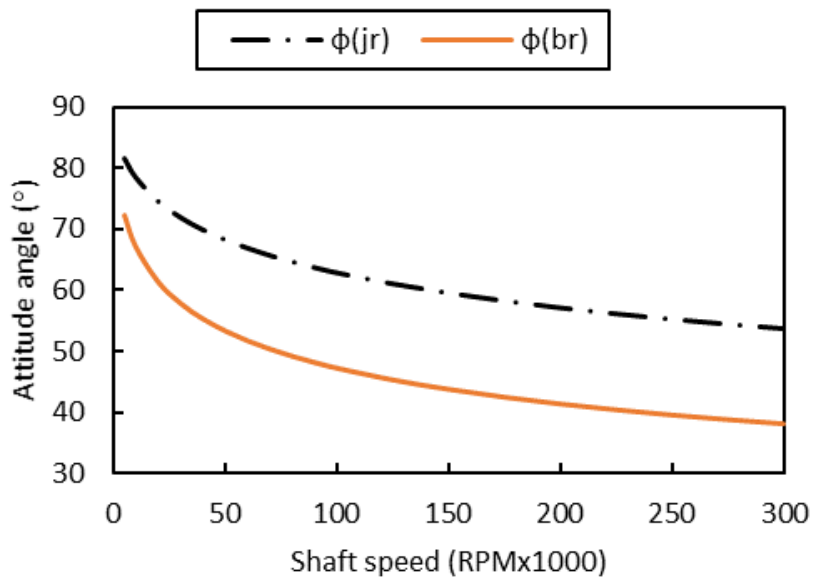

Fig. 6: Variation of attitude angles with shaft speed for the journalfloating ring (jr) and floating ring-bearing (br) conjunctions

Figure 7 shows the increase in oil pressure with shaft speed due to an increase in unbalanced loading. The greater pressure at the shaftfloating ring conjunction is also in line with the effect of a smaller clearance at this conjunction as observed earlier in Figures 3 and 4.

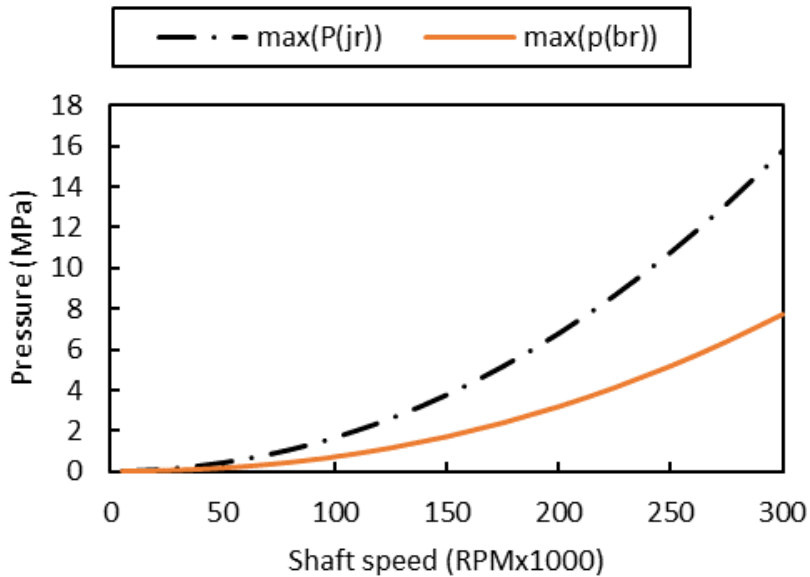

Fig. 7: Variation of maximum pressure with shaft speed at the journal-floating ring (jr) and floating ring-bearing (br) conjunctions

Figure 8 shows the results for the rotational frequency and journalfloating ring speed ratio, while shaft speed is swept through 0 to 300,000 RPM. Floating ring speed increases proportionally with the shaft speed due to the viscous friction at its interface with the lubricant film. This proportionality is not linear and varies almost logarithmically with the shaft speed. Hence, the floating ring speed gradually stabilises with the increase in shaft speed.

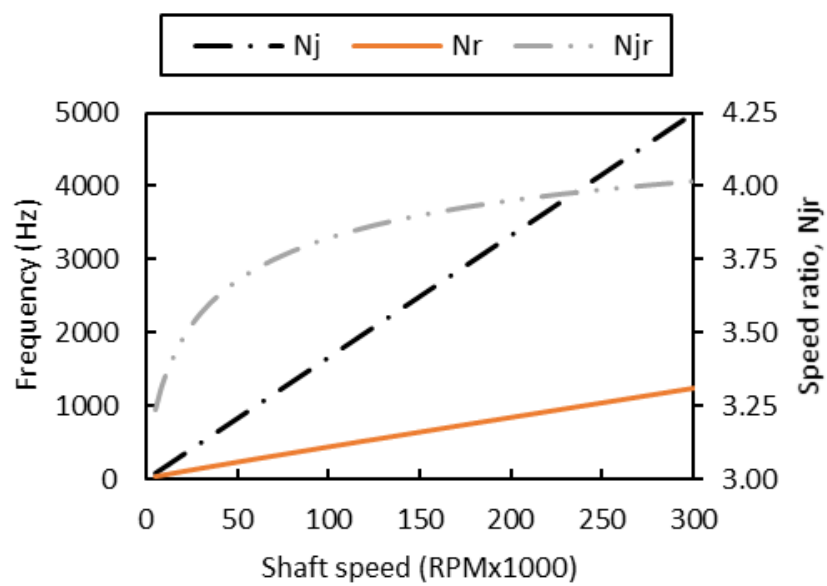

Fig. 8: Floating ring and shaft rotational frequency variations with shaft speed in comparison with the speed ratio of journal to floating ring

Shaft rotational speed imposes certain vibrations in turbochargers. The main frequency of vibration is the shaft frequency (i.e. the outof-balance response). A few sub-synchronous frequencies are also present due to contributions from the lubricant film stiffness and the structural flexibility of the shaft. The main sub-synchronous frequency occurs at almost half the shaft frequency. This is known as the oil whirl $[9,13]$. To predict oil whirl/whip, the two-dimensional damped frequency model described earlier is used. Figure 9 shows the variation of main turbocharger frequencies with shaft speed. Whirl at the journal-floating ring conjunction appears up to $\sim 15,000$ RPM. It is observed that the whirl frequency is variable and slightly greater than half of the shaft frequency. Oil whirl lasts longer at the floating ring-bearing conjunction ( 30,000 RPM). Oil whirl frequency at this conjunction follows more closely the half floating ring speed. The results in Koutsovasilis et al [8] also show the presence of the first sub-synchronous mode at frequencies below 500 $\mathrm{Hz}$. This frequency range is in reasonable agreement with those in Figure 9. At higher shaft speeds, oil film vibration frequency stabilises, and oil whip is dominant.

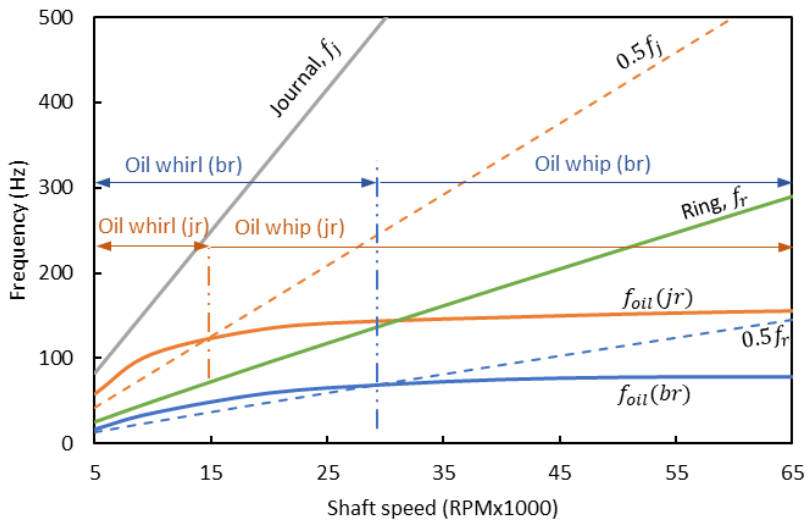

Fig. 9: Oil frequencies at the shaft-ring (jr) and floating ring-bearing (br) conjunctions including the lubricant damping effects and relative motions of journal and ring 
Noise and frictional losses are inversely proportional in tribological contacts at constant load levels. However, unbalanced load and film thickness simultaneously vary with shaft speed in turbochargers. Hence, sound pressure level (SPL) and power loss increase with shaft speed as shown in Figure 10. Therefore, the growth rate in $\mathrm{NVH}$ signature and friction seem to be inversely related.

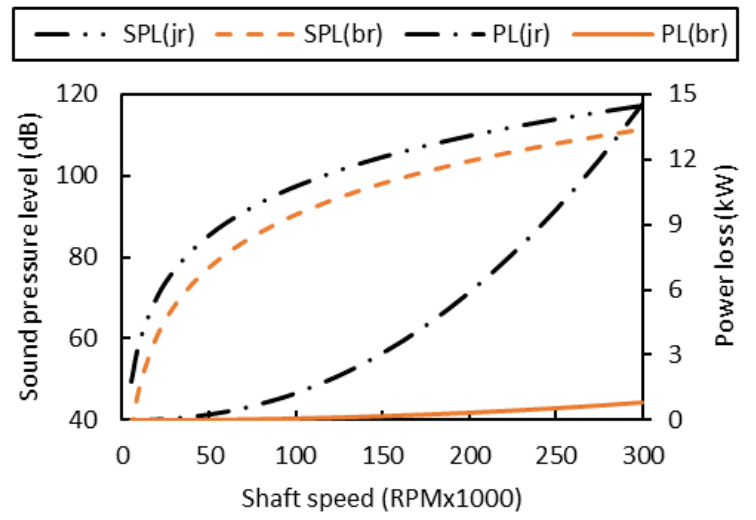

Fig. 10: Comparison of the trends in sound pressure levels and power losses at the shaft-floating ring (jr) and floating ring-bearing (br) conjunctions

\section{Conclusion}

The aim of this study is to obtain an estimation of sound pressure levels from floating ring journal bearings of turbochargers. Therefore, an analytical model, based on short-width journal bearing assumption is developed for the study of floating ring bearings encountered in modern turbochargers. The model is able to approximately predict pressure distribution, film thickness and generated viscous friction in the bearing for a wide range of journal speeds, which is also representative of its unbalanced loading. In addition, using a twodimensional stability model, it is shown that the rotational speed for transition from oil whirl to oil whip in the contact between the floating ring and the bearing can be almost twice that of journal and floating ring. The associated sub-synchronous vibrations are the major sources of noises emission from the bearings. The assessment of generated sound pressure levels shows that its growth has a decreasing trend with rotor speed. This is opposite to the behaviour observed in bearing efficiency, measured based on frictional power loss. It is observed that the highest frictional power loss is associated with the contact between the journal and the floating ring, whilst the contribution to sound pressure level is also greater in this conjunction. The developed analytical model provides a convenient and easy to use computational tool for assessment of the bearing design parameters effect on the energy efficiency and noise signatures from turbocharger bearings.

\section{References}

[1] Bernhauser, L., Steinwender, L. and Neumayer, R., "Efficient run-up simulations for the investigation of acoustically relevant vibrations of turbocharger structures with floating-ring bearings", In Proceedings of the DAGA 2016, Aachen, Germany

Page 6 of 7
[2] Kirk, R.G. and Alsaeed, A.A., "Stability analysis of a highspeed automotive turbocharger", Tribology Transactions, 2007, 50(3), pp. 427-434

[3] Tian, L., Wang, W.J. and Peng, Z.J., "Dynamic behaviours of a full floating ring bearing supported turbocharger rotor with engine excitation", Journal of Sound and Vibration, 2011, 330, pp. 4851-4874

[4] Schweizer, B. and Sievert, M., "Nonlinear oscillations of automotive turbocharger turbines", Journal of Sound and Vibration, 2009, 321(3-5), pp. 955-975.

[5] San Andres, L., Rivadeneira, J.C., Chinta, M., Gjika, K. and La Rue, G., "Nonlinear rotordynamics of automotive turbochargers: predictions and comparisons to test data", Journal of Engineering for Gas Turbines and Power, 2007, 129(2), pp. 488-493

[6] Brouwer, M.D., Sadeghi, F., Lancaster, C., Archer, J. and Donaldson, J., "Whirl and friction characteristics of high speed floating ring and ball bearing turbochargers", Journal of Tribology, 2013, 135(4):041102.

[7] Smolik, L., Hajzman, M. and Byrtus, M., "Investigation of bearing clearance effects in dynamics of turbochargers", International Journal of Mechanical Sciences, 2017, 127, pp. 62-72.

[8] Koutsovasilis, P., Driot, N., Lu, D. and Schweizer, B., "Quantification of sub-synchronous vibrations for turbocharger rotors with full-floating ring bearings", Archive of Applied Mechanics, 2015, 85, pp. 481-502.

[9] Gohar, R. and Rahnejat, "Fundamentals of Tribology", Imperial College Press, London, 2008.

[10] Mokhrtar MOA. Floating ring journal bearings: theory, design and optimization. Tribology International. 1981, 14(2), pp. 113-119.

[11] Rho, B.H. and Kim, K.W., "Acoustical properties of hydrodynamic journal bearings", Tribology International, 2003, 36, pp. 61-66.

[12] Mohammadpour, M., Rahmani, R. and Rahnejat, H., "Effect of cylinder deactivation on the tribo-dynamics and acoustic emission of overlay big end bearings", Proceedings of the Institution of Mechanical Engineers, Part K: Journal of Multi-body Dynamics, 2014, 228(2), pp. 138-151.

[13] Cameron, A., "The principles of lubrication", John Wiley, 1966.

\section{Contact Information}

Dr Nader Dolatabadi, Email: N.Dolatabadi@lboro.ac.uk, Tel: +44 1509227114. 


\section{Nomenclature}

$[\mu \mathrm{m}]$

C Bearing clearance

[m]

[m]

[N]

$[\mathrm{Hz}]$

[m]

[m]

$\left[\mathrm{N} / \mathrm{m}^{2}\right]$

[m]

[N.m]

[g]

[g.mm]

[g.mm]

[rps]

$[\mathrm{Pa}]$

$[\mathrm{Pa}]$

$[\mathrm{Pa}]$

$p_{m} \quad$ Average pressure of oil film

$p_{\max }$ Maximum pressure of oil film $p_{\text {ref }} \quad$ Reference pressure

[Pa]

$R$ Radius [m]

$T$ Temperature [K]

$T_{c} \quad$ Period of one bearing rotational cycle [s]

$t \quad$ Time

$U \quad$ Entrainment velocity

$\Delta \quad$ Sommerfeld number

[s]

$[\mathrm{m} / \mathrm{s}]$

$\varepsilon \quad$ Eccentricity ratio

$\eta \quad$ Dynamic viscosity

$[-]$

$[-]$ [Pa.s]

$\theta \quad$ Angular position along the bearing periphery [rad]

$\lambda \quad$ Whirl/whip frequency $\quad[\mathrm{rad} / \mathrm{s}]$

$\tau \quad$ Viscous shear stress $\quad[\mathrm{Pa}]$

$\phi \quad$ Attitude angle [rad]

$\chi \quad$ Relaxation factor

$\omega \quad$ Angular velocity

$\Omega \quad$ Nondimensional rotation speed of shaft

$\Omega_{j} \quad$ Shaft speed
[-] $[\mathrm{rad} / \mathrm{s}]$

[-]

[RPM] 